Revista Brasileira de Cartografia

ISSN 1808-0936 | https://doi.org/10.14393/revbrascartogr

Sociedade Brasileira de Cartografia, Geodésia, Fotogrametria e Sensoriamento Remoto

\title{
Estimativas do Nível do Mar na América do Sul a partir de Registros Maregráficos e Coordenadas SIRGAS-CON
}

\author{
Sea Level Estimates in South America from Tide Gauge Records and SIRGAS-CON \\ Coordinates
}

Lucas Gonzales Lima Pereira Calado ${ }^{1}$, Silvio Jacks dos Anjos Garnés ${ }^{2}$ e Karoline Paes Jamur ${ }^{3}$

1 Universidade Federal de Pernambuco, Programa de Pós-graduação em Ciências Geodésicas e Tecnologias da Geoinformação, Recife, Brasil. calado.lucaslima@gmail.com

ORCID: https://orcid.org/0000-0002-2456-8288

2 Universidade Federal de Pernambuco, Programa de Pós-graduação em Ciências Geodésicas e Tecnologias da Geoinformação, Recife, Brasil. silviogarnes@gmail.com

ORCID: https://orcid.org/0000-0002-0098-6645

3 Universidade Federal de Pernambuco, Programa de Pós-graduação em Ciências Geodésicas e Tecnologias da Geoinformação,

Recife, Brasil.karoljamur@gmail.com

ORCID: https://orcid.org/0000-0003-0087-3197

Resumo: Neste estudo, avaliou-se a taxa relativa do nível do mar em 20 estações maregráficas, com dados mensais do Permanet Service for Mean Sea Level (PSMSL), na América do Sul. Para a estimativa do movimento vertical crustal foram utilizadas 12 estações do Global Navigation Satellite System (GNSS) da rede de monitoramento contínuo do Sistema de Referência Geocêntrico para as Américas (SIRGAS-CON), que ficam nas proximidades do marégrafo a uma distância máxima de $10 \mathrm{~km}$. Com o conhecimento da variação vertical, foi possível obter a taxa absoluta do nível do mar para 12 estações maregráficas. A análise estatística se procedeu pela regressão linear (linha de tendência) e regressão polinomial quadrática (aceleração). Assim, na América do Sul, a taxa de variação média do nível absoluto do mar resultou em 0,98 mm/ano $\pm 0,93 \mathrm{~mm} /$ ano, para um período médio de 1950 a 2018.

Palavras-chave: América do Sul. Movimento vertical crustal. Nível do mar.

Abstract: In this study, the relative sea level rate was evaluated in 20 maregraphic stations, with monthly data from the Permanent Service for Mean Sea Level (PSMSL), in South America. To estimate the crustal vertical movement, 12 stations from the Global Navigation Satellite System (GNSS) of the Geocentric Reference System for the Americas (SIRGAS-CON) continuous monitoring network, which is located near the tide gauge at a maximum distance of $10 \mathrm{~km}$. With the knowledge of vertical variation, it was possible to obtain the absolute sea level rate for 12 sea stations. Statistical analysis was performed by linear regression (trend line) and quadratic polynomial regression (acceleration). Thus, in South America, the average rate of change in absolute sea level resulted in $0.98 \mathrm{~mm} / \mathrm{year} \pm 0.93 \mathrm{~mm} / \mathrm{year}$ for an average period from 1950 to 2018 .

Keywords: South America. Crustal vertical movement. Sea level.

\section{INTRODUÇÃO}

O aumento do nível do mar está associado às mudanças relacionadas ao clima, as temperaturas oceânicas e ao derretimento das geleiras, e nos últimos 25 anos, o derretimento das geleiras da Antártida, por exemplo, segundo Imbie (2018), ocasionou um aumento de 7,6 milímetros no nível médio dos mares. As técnicas utilizadas para encontrar tais variações, envolvem dados regionais e globais por meio de medições: maregráficas, de sensores flutuantes, de altimetria e gravimetria por satélite (GGOS, 2019).

As consequências da elevação do nível do mar no século XXI tem afetado a infraestrutura, os ecossistemas e as vidas de pessoas no mundo, de maneira que o nível médio dos mares serve como um indicador do impacto social. O Global Geodetic Observing System (GGOS), definiu como um dos temas de 
estudo a "Alteração, Variabilidade e Previsão do Nível do Mar - Sea Level Change, Variability, and Forecasting", que tem como foco principal demonstrar as técnicas geodésicas disponíveis para verificar o aumento do nível do mar, incluindo estudos dos impactos de sua mudança sobre as regiões e ilhas costeiras do mundo (GGOS, 2019).

Muitos pesquisadores vêm abordando a temática do nível do mar nos últimos anos. Dalazoana, Luz e De Freitas (2005), integraram séries temporais armazenadas no banco de dados do Serviço Permanente para o Nível Médio do Mar (Permanent Service for Mean Sea Level - PSMSL) e dados digitais para obtenção do Nível Médio do Mar no Porto de Imbituba, obtiveram uma elevação em torno de 2 mm/ano. Fiore et al. (2008), obtiveram um aumento do nível do mar relativo, na costa da província de Buenos Aires, na Argentina, da ordem de 1,5 mm/ano. Da Silva, De Freitas e Dalazoana (2016), identificam uma variação temporal absoluta do nível do mar de aproximadamente $2,4 \mathrm{~mm} / \mathrm{ano} \pm 0,2 \mathrm{~mm} /$ ano na região do Datum Vertical Brasileiro de Imbituba. López, Cevallos e Torres (2017), reúnem 23 séries maregráficas de longa duração no litoral do Pacífico Sul Oriental e, ajustando uma tendência linear, chegam a uma variação de $-4,0 \mathrm{~mm} / \mathrm{ano}$ até 5,7 mm/ano para a região em estudo. Albarici, Guimarães e Trabanco (2018), analisaram o nível médio do mar relativo para a estação de Cananeia, em São Paulo, e obtiveram uma elevação de 3,8 mm/ano para o período de 1955-2007. Calado, Garnés e Jamur (2018), determinaram as variações do nível do mar relativo na estação maregráfica de Fortaleza, obtendo uma taxa de aumento de 2,2 mm/ano no período 2008-2015, mas com indicativa de diminuição da taxa pela desaceleração do modelo quadrático. Tal expectativa foi confirmada pelos autores quando a série considerou o período de 2008-2018, cuja taxa de aumento do nível relativo pela regressão linear foi de $0,6 \mathrm{~mm} / \mathrm{ano}$.

Nesse estudo, tem-se como objetivo estimar as taxas de mudança relativa do nível do mar com registros maregráficos mensais do banco de dados do PSMSL e, com as coordenadas semanais das estações da rede de monitoramento contínuo SIRGAS-CON, a taxa de mudança absoluta do nível do mar para a América do Sul. As estimativas serão realizadas por meio de análises estatísticas de regressão linear e regressão polinomial quadrática, utilizando 20 estações maregráficas e 12 estações GNSS.

\section{MATERIAIS E MÉTODOS}

Nesta sessão são descritos os tipos de dados maregráficos e GNSS e as fontes públicas de onde foram obtidos, bem como os locais escolhidos para proceder as análises. Descreve-se também as principais equações e o procedimento aplicado para a obtenção dos resultados.

\subsection{Estações maregráficas}

Os marégrafos são as fontes de medições históricas do nível do mar com precisão. Os registros obtidos nas estações maregráficas têm sido, tradicionalmente, usados para avaliar o nível do mar para fins de navegação, para estudar e prever marés em um determinado local. Na Geodésia é utilizado para definir o nível médio do mar na definição do Datum de Sistemas Verticais de Referência Clássicos.

No presente estudo, os dados de nível do mar, das estações maregráficas, foram obtidos do banco de dados do PSMSL (HOLGATE et al., 2013; PSMSL, 2019). As séries temporais de medições do nível do mar utilizadas em cada estação, foram as reduzidas a mesma superfície de referência (mesmo datum origem). Essa redução é realizada pelo PSMSL a uma Referência Local Revisada (RLR). O ponto de referência RLR em cada estação é definido como sendo aproximadamente 7,0 metros abaixo do nível médio do mar para evitar valores negativos nas médias do RLR resultante (PSMSL, 2019).

Os marégrafos disponíveis para a América do Sul, utilizados neste estudo, foram selecionados de acordo com os seguintes critérios:

a) registros iguais ou maiores a 20 anos;

b) contínuos, ou seja, com menos de $10 \%$ de valores ausentes;

c) caso tenha dois marégrafos no mesmo local, utiliza-se o marégrafo com série temporal de maior duração. 
Na Tabela 1, encontram-se as informações das estações maregráficas: País, identificação, nome da estação, latitude e longitude, início e fim da série temporal, número de anos da série, quantidade de dados mensais, quantidade de dados mensais faltantes e porcentagem de dados mensais faltantes.

As 20 séries maregráficas que foram analisadas apresentam as seguintes características: oito estações superam os 50 anos de registro, cinco delas possuem mais de 30 anos e sete superam os 20 anos de representação temporal.

Tabela 1 - Estações maregráficas.

\begin{tabular}{|c|c|c|c|c|c|c|c|c|c|}
\hline País & $\begin{array}{c}\text { Id da } \\
\text { estação }\end{array}$ & $\begin{array}{l}\text { Nome da } \\
\text { estação }\end{array}$ & $\begin{array}{r}\text { Localização } \\
\text { (Lat Long) }\end{array}$ & Início & Fim & $\begin{array}{l}\mathrm{N}^{\circ} \text { de } \\
\text { anos }\end{array}$ & $\begin{array}{l}\text { Quant. de } \\
\text { dados } \\
\text { mensais }\end{array}$ & $\begin{array}{c}\text { Quant. de } \\
\text { dados } \\
\text { mensais } \\
\text { faltantes }\end{array}$ & $\begin{array}{c}\text { Dados } \\
\text { mensais } \\
\text { faltantes }(\%)\end{array}$ \\
\hline \multirow{4}{*}{ 岕 } & 157 & Buenos Aires & $\begin{array}{l}-34,600000^{\circ} \\
-58,366667^{\circ}\end{array}$ & $01 / 1905$ & $12 / 1987$ & 83 & 996 & 0 & - \\
\hline & 223 & Quequen & $\begin{array}{l}-38,583333^{\circ} \\
-58,700000^{\circ}\end{array}$ & $01 / 1918$ & $12 / 1982$ & 65 & 780 & 12 & 1,54 \\
\hline & 819 & Mar Del Plata & $\begin{array}{l}-38,033333^{\circ} \\
-57,516667^{\circ}\end{array}$ & $07 / 1957$ & $12 / 2017$ & 60 & 726 & 30 & 4,13 \\
\hline & 832 & Palermo & $\begin{array}{r}-34,566667^{\circ} \\
-58,400000^{\circ} \\
\end{array}$ & $07 / 1957$ & $12 / 2017$ & 60 & 726 & 13 & 1,79 \\
\hline \multirow{6}{*}{$\underset{\frac{a}{n}}{\overleftarrow{n}}$} & 542 & Imbituba & $\begin{array}{l}-28,233333^{\circ} \\
-48,650000^{\circ}\end{array}$ & $09 / 1948$ & $12 / 1968$ & 20 & 244 & 0 & - \\
\hline & 556 & Recife & $\begin{array}{r}-8,050000^{\circ} \\
-34,866667^{\circ}\end{array}$ & $10 / 1948$ & $12 / 1968$ & 20 & 243 & 0 & - \\
\hline & 578 & Salvador & $\begin{array}{l}-12,966667^{\circ} \\
-38,516667^{\circ}\end{array}$ & $01 / 1949$ & $12 / 1968$ & 20 & 240 & 7 & 2,92 \\
\hline & 580 & Belém & $\begin{array}{c}-1,450000^{\circ} \\
-48,500000^{\circ}\end{array}$ & $01 / 1949$ & $12 / 1968$ & 20 & 240 & 0 & - \\
\hline & 726 & Cananéia & $\begin{array}{l}-25,016667^{\circ} \\
-47,933333^{\circ} \\
\end{array}$ & $03 / 1954$ & $12 / 2006$ & 53 & 634 & 19 & 3,00 \\
\hline & 1032 & Ilha Fiscal & $\begin{array}{l}-22,896667^{\circ} \\
-43,166667^{\circ}\end{array}$ & $02 / 1963$ & $12 / 2016$ & 54 & 647 & 33 & 5,10 \\
\hline \multirow{4}{*}{ 丞 } & 510 & Antofagasta 2 & $\begin{array}{l}-23,653056^{\circ} \\
-70,404444^{\circ}\end{array}$ & $12 / 1945$ & $12 / 2017$ & 72 & 865 & 61 & 7,05 \\
\hline & 571 & Talcahuano & $\begin{array}{l}-36,683333^{\circ} \\
-73,100000^{\circ}\end{array}$ & 08/1949 & $12 / 2017$ & 68 & 821 & 51 & 6,21 \\
\hline & 619 & Caldera & $\begin{array}{l}-27,066667^{\circ} \\
-70,833333^{\circ} \\
\end{array}$ & $12 / 1950$ & $12 / 1991$ & 41 & 493 & 6 & 1,22 \\
\hline & 2261 & Iquique II & $\begin{array}{l}-20,204444^{\circ} \\
-70,147778^{\circ}\end{array}$ & $10 / 1984$ & $12 / 2017$ & 33 & 339 & 20 & 5,01 \\
\hline \multirow{2}{*}{ రิ } & 456 & Buenaventura & $\begin{array}{c}3,900000^{\circ} \\
-77,100000^{\circ}\end{array}$ & $01 / 1941$ & $12 / 1969$ & 29 & 348 & 32 & 9,20 \\
\hline & 572 & Cartagena & $\begin{array}{l}10,400000^{\circ} \\
-75,550000^{\circ}\end{array}$ & $01 / 1949$ & $12 / 1992$ & 44 & 528 & 24 & 4,55 \\
\hline$\underset{8}{8}$ & 544 & La Libertad II & $\begin{array}{r}-2,200000^{\circ} \\
-80,916667^{\circ} \\
\end{array}$ & $10 / 1948$ & $12 / 1994$ & 46 & 555 & 23 & 4,14 \\
\hline \multirow{3}{*}{$\frac{\alpha}{\frac{1}{2}}$} & 458 & Matarani & $\begin{array}{l}-17,000000^{\circ} \\
-72,116667^{\circ}\end{array}$ & $05 / 1941$ & $12 / 1969$ & 29 & 334 & 18 & 5,23 \\
\hline & 475 & Talara & $\begin{array}{r}-4,616667^{\circ} \\
-81,283333^{\circ}\end{array}$ & $01 / 1942$ & $12 / 1969$ & 28 & 336 & 0 & - \\
\hline & 1274 & Callao 2 & $\begin{array}{l}-12,050000^{\circ} \\
-77,150000^{\circ}\end{array}$ & 01/1970 & $10 / 2016$ & 47 & 562 & 5 & 0,89 \\
\hline
\end{tabular}

Fonte: Adaptada de PSMSL (2019).

Os marégrafos selecionados estão distribuídos da seguinte forma: quatro na Argentina, seis no Brasil, quatro no Chile, dois na Colômbia, um no Equador e três no Peru. A Figura 1 ilustra as suas localizações geográficas. 
Figura 1 - Estações maregráficas com séries temporais com mais de 20 anos de dados na América do Sul e estações GNSS da rede SIRGAS-CON próximas aos marégrafos.

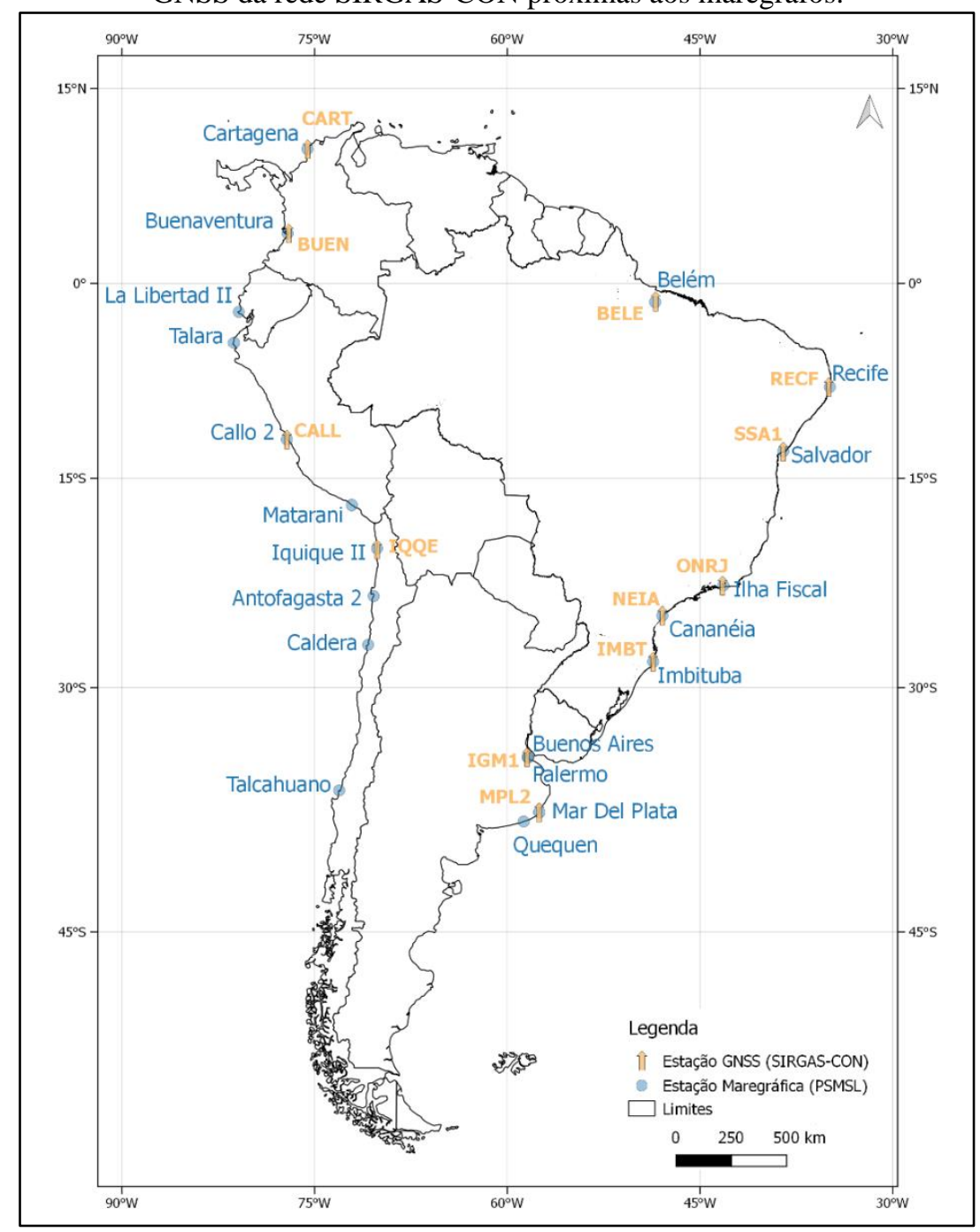

Fonte: Os autores (2020).

\subsection{Estações GNSS}

Para poder analisar o movimento vertical crustal, foram utilizados os produtos GNSS do processamento da rede SIRGAS-CON disponíveis no site do SIRGAS: <http://www.sirgas.org/pt/sirgas-connetwork/coordinates/>. Nele, é possível obter as soluções semanais semilivres, as coordenadas semanais das estações, e as soluções multianuais. Entretanto, para este trabalho, foram utilizadas as coordenadas semanais das estações.

As coordenadas semanais finais são geradas para toda rede SIRGAS-CON a partir da combinação das soluções individuais proporcionadas pelos centros de processamento SIRGAS. Os arquivos com a extensão CRD (coordenadas) contém as posições semanais finais das estações e os arquivos com a extensão SUM (sumário) são os relatórios da semana correspondente. Tais arquivos são disponibilizados no site <ftp://ftp.sirgas.org/pub/gps/SIRGAS/>.

Foram selecionados todos os arquivos CRD, com as coordenadas finais, disponíveis no site do SIRGAS até a semana GPS 2033, que corresponde a semana entre os dias 24 e 28 de dezembro de 2018. Desses arquivos foram selecionadas as estações que se encontram mais próximas aos marégrafos estudados, num raio máximo de $10 \mathrm{~km}$ (esta distância tem influência inferior ao décimo do milímetro nos resultados face a variação da inclinação da placa tectônica). A Tabela 2 informa o país, a identificação da estação, a latitude e longitude em graus decimais, a cidade, a data de início da série, a data final da série, o número de anos da série, a quantidade de dados semanais da estação, a quantidade de dados semanais faltantes, a porcentagem de dados semanais faltantes e o status da estação. A Figura 1 ilustra também, a posição geográfica das estações GNSS, 
SIRGAS-CON, utilizadas na análise.

Tabela 2 - Estações GNSS.

\begin{tabular}{|c|c|c|c|c|c|c|c|c|c|}
\hline Id Est & $\begin{array}{c}\text { Localização } \\
\text { (Lat Long) }\end{array}$ & $\begin{array}{l}\text { Cidade } \\
\text { País }\end{array}$ & Início & Fim & $\begin{array}{c}\mathbf{N}^{\circ} \\
\text { de } \\
\text { anos }\end{array}$ & $\begin{array}{l}\text { Quant. de } \\
\text { dados } \\
\text { semanais }\end{array}$ & $\begin{array}{l}\text { Quant. de } \\
\text { dados } \\
\text { semanais } \\
\text { faltantes }\end{array}$ & $\begin{array}{c}\text { Dados } \\
\text { semanais } \\
\text { faltantes } \\
(\%)\end{array}$ & Status \\
\hline IGM1 & $\begin{array}{l}-34^{\circ} 34^{\prime} 20^{\prime \prime} \\
-58^{\circ} 26^{\prime} 22^{\prime \prime}\end{array}$ & $\begin{array}{c}\text { Buenos Aires } \\
\text { Argentina }\end{array}$ & $09 / 11 / 2003$ & $26 / 12 / 2018$ & 15 & 756 & 5 & 0,66 & Ativa \\
\hline MPL2 & $\begin{array}{l}-38^{\circ} 02^{\prime} 08^{\prime \prime} \\
-5731 \text { '52”' }\end{array}$ & $\begin{array}{c}\text { Mar Del Plata } \\
\text { Argentina }\end{array}$ & $11 / 11 / 2009$ & $26 / 12 / 2018$ & 9 & 387 & 61 & 13,62 & Ativa \\
\hline BELE & $\begin{array}{l}-01^{\circ} 24^{\prime} 32^{\prime \prime} \\
-48^{\circ} 27^{\prime} 45^{\prime \prime}\end{array}$ & $\begin{array}{l}\text { Belém } \\
\text { Brasil }\end{array}$ & 02/01/2004 & $26 / 12 / 2018$ & 14 & 740 & 14 & 1,86 & Ativa \\
\hline IMBT & $\begin{array}{l}-28^{\circ} 14^{\prime} 05^{\prime \prime} \\
-48^{\circ} 39^{\prime} 21^{\prime \prime}\end{array}$ & $\begin{array}{c}\text { Imbituba } \\
\text { Brasil }\end{array}$ & 05/09/2007 & $26 / 12 / 2018$ & 11 & 552 & 10 & 1,78 & Ativa \\
\hline NEIA & $\begin{array}{l}-25^{\circ} 01^{\prime} 13^{\prime \prime} \\
-47^{\circ} 55^{\prime} 30^{\prime \prime}\end{array}$ & $\begin{array}{c}\text { Cananeia } \\
\text { Brasil }\end{array}$ & 04/01/2006 & $26 / 12 / 2018$ & 12 & 615 & 34 & 5,24 & Ativa \\
\hline ONRJ & $\begin{array}{l}-22^{\circ} 53^{\prime} 45^{\prime \prime} \\
-43^{\circ} 13^{\prime} 28^{\prime \prime}\end{array}$ & $\begin{array}{c}\text { Ilha Fiscal } \\
\text { Brasil }\end{array}$ & 04/04/2007 & $26 / 12 / 2018$ & 11 & 584 & 3 & 0,51 & Ativa \\
\hline RECF & $\begin{array}{l}-08^{\circ} 03^{\prime} 03^{\prime \prime} \\
-34^{\circ} 57^{\prime} 05^{\prime \prime}\end{array}$ & $\begin{array}{l}\text { Recife } \\
\text { Brasil }\end{array}$ & $19 / 01 / 2000$ & $21 / 02 / 2018$ & 18 & 876 & 69 & 7,30 & Desativada \\
\hline SSA1 & $\begin{array}{l}-12^{\circ} 58^{\prime} 31^{\prime \prime} \\
-38^{\circ} 30^{\prime} 59^{\prime \prime}\end{array}$ & $\begin{array}{c}\text { Salvador } \\
\text { Brasil }\end{array}$ & 05/09/2007 & $26 / 12 / 2018$ & 11 & 560 & 2 & 0,36 & Ativa \\
\hline IQQE & $\begin{array}{l}-20^{\circ} 16^{\prime} 25^{\prime \prime} \\
-70^{\circ} 07^{\prime} 54^{\prime \prime}\end{array}$ & $\begin{array}{l}\text { Iquique } \\
\text { Chile }\end{array}$ & 03/07/2002 & $05 / 12 / 2018$ & 16 & 604 & 220 & 26,70 & Ativa \\
\hline BUEN & $\begin{array}{l}03^{\circ} 53^{\prime} 55^{\prime \prime} \\
-77^{\circ} 00^{\prime} 38^{\prime \prime}\end{array}$ & $\begin{array}{c}\text { Buenaventura } \\
\text { Colômbia }\end{array}$ & $05 / 10 / 2005$ & $26 / 12 / 2018$ & 13 & 522 & 140 & 21,15 & Ativa \\
\hline CART & $\begin{array}{l}10^{\circ} 23^{\prime} 29^{\prime \prime} \\
-75^{\circ} 32^{\prime} 02^{\prime \prime}\end{array}$ & $\begin{array}{l}\text { Cartagena } \\
\text { Colômbia }\end{array}$ & $02 / 02 / 2000$ & $28 / 11 / 2018$ & 18 & 407 & 550 & 57,47 & Ativa \\
\hline CALL & $\begin{array}{l}-12^{\circ} 03^{\prime} 46^{\prime \prime} \\
-77^{\circ} 08^{\prime} 58^{\prime \prime}\end{array}$ & $\begin{array}{c}\text { Callao } \\
\text { Peru }\end{array}$ & 29/07/2009 & $25 / 04 / 2018$ & 9 & 412 & 45 & 9,85 & Removida \\
\hline
\end{tabular}

Fonte: Adaptada de SIRGAS (2019).

As coordenadas SIRGAS são disponibilizadas por dois centros de combinação: Instituto Brasileiro de Geografia e Estatística (IBGE) e IGS Regional Network Associate Analysis Centre for SIRGAS (IGS-RNAACSIR). Desde o dia 1 de janeiro de 2012, as soluções combinadas pelo IBGE fornecem as posições semanais oficiais das estações, enquanto as soluções combinadas calculadas pelo IGS-RNAAC-SIRGAS possibilitam controle e cópia de segurança (SIRGAS, 2019). Para este trabalho foram utilizadas as coordenadas disponibilizadas pelos dois centros, sendo que as coordenadas do IBGE serviram para validar as coordenadas fornecidas pelo IGS, obtendo uma correlação maior que $99 \%$ em todas as estações analisadas.

As coordenadas são disponibilizadas no Sistema Cartesiano Geocêntrico. Para poder proceder a análise, deve-se ter a altitude geodésica (elipsoidal). Portanto, as coordenadas foram transformadas de Cartesianas Geocêntricas (X, Y, Z) para Geodésicas Elipsoidais (Latitude Geodésica, Longitude Geodésica, Altitude Geodésica), referidas ao elipsoide GRS-80.

\subsection{Nível do mar relativo}

Os marégrafos medem as variações do nível do mar como variações na posição relativa entre a superfície do mar e uma Referência de Nível (RN) permanente em Terra. É usual a existência de várias Referências de Nível (RRNN) na região do marégrafo para evitar possíveis transtornos quanto à destruição de alguma delas (DALAZOANA e DE FREITAS, 2006).

Esse sistema local dificulta a comparação de dados de diferentes estações e a distinção entre a mudança do nível do mar e os movimentos de terra, pois a RN pode ter movimentos verticais a uma taxa muito próxima ao sinal do nível do mar. Os movimentos verticais no local do marégrafo podem ser causados por marés terrestres, movimentos tectônicos, isostasia, efeitos de carga e movimentos artificiais (induzidos pelo Homem). Assim, o movimento vertical da crosta terrestre e as variações do nível do mar estão incluídos nos registros maregráficos. Apesar de que, para escalas de tempo curtas, os movimentos verticais possam ser insignificantes, a longo prazo os movimentos da crosta constituem efeitos locais e regionais com a mesma importância que os efeitos responsáveis pelas mudanças no nível dos mares (BARBOSA, 2005). 
Segundo Barbosa (2005), esses problemas impedem as estimativas de mudança do nível do mar somente com as medições dos marégrafos, pois, assim, obtêm-se o nível do mar relativo à superfície terrestre. Porém, os sinais terrestres nos registros dos marégrafos são corrigidos usando estimativas a partir de técnicas geodésicas espaciais ou de modelos de recuperação pós-glacial e, os movimentos verticais podem ser discretizados através de técnicas GNSS e utilizando gravidade absoluta.

\subsection{Nível do mar absoluto ou geocêntrico}

Como visto anteriormente, as estações maregráficas podem ser afetadas por movimentos verticais terrestres, pois os marégrafos fornecem o nível do mar relativo. Então, com o conhecimento da velocidade vertical crustal obtida através das observações GNSS é possível obter o valor do nível do mar absoluto $(\Delta H)$ para uma futura comparação com altímetros orbitais através da Equação 1. A Figura 2 apresenta a relação entre os elementos da equação.

$$
\Delta H=\Delta N+\Delta h=H_{t_{2}}-H_{t_{1}}
$$

Figura 2 - Representação para obtenção do valor do nível do mar absoluto integrando estações maregráficas e estações GNSS.

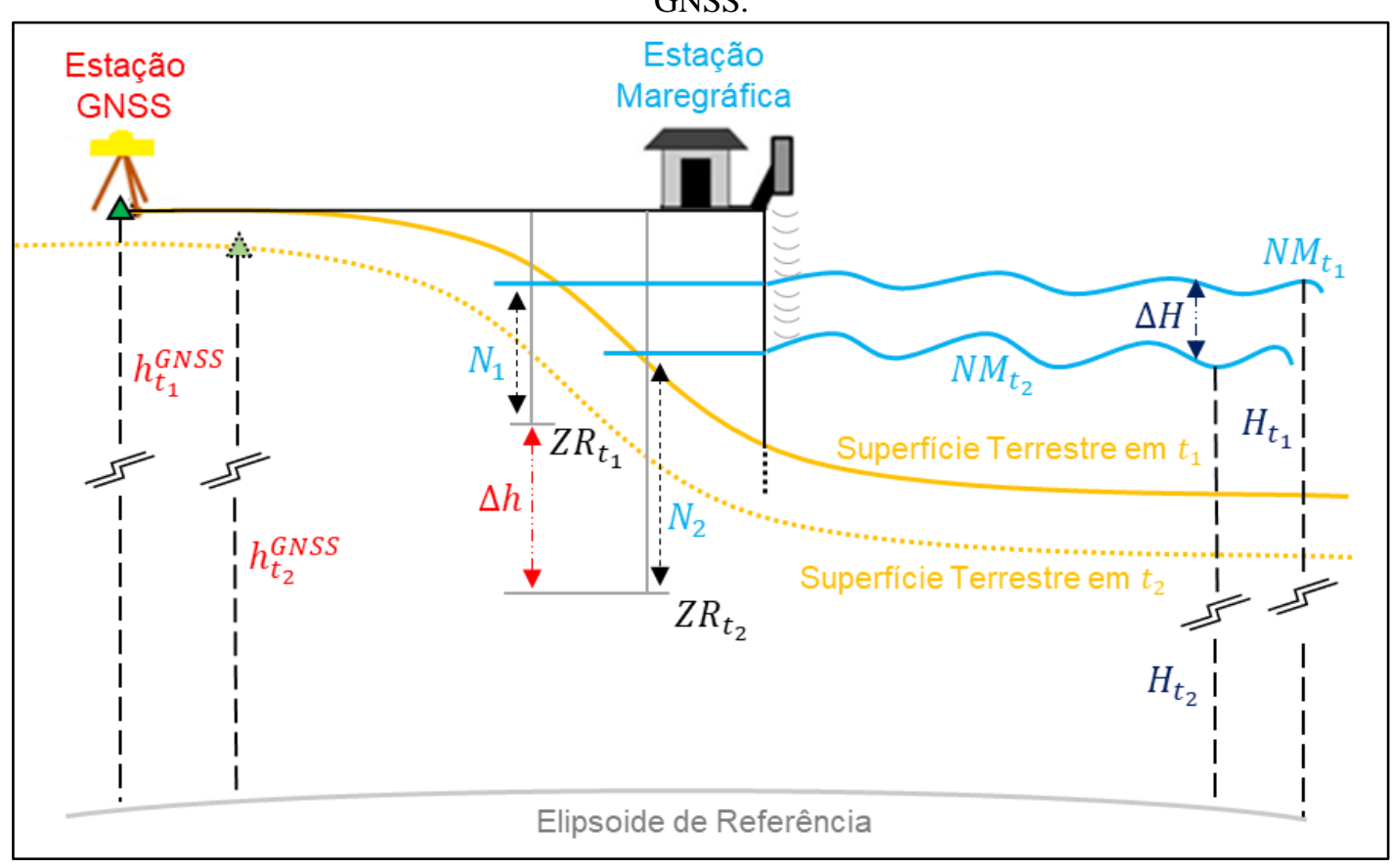

Fonte: Os autores (2020).

sendo:

- $H_{t_{1}}$ e $H_{t_{2}}$ corresponde à altitude do nível do mar obtido por altímetros orbitais para as épocas $t_{1}$ e $t_{2}$, respectivamente, referidas ao elipsoide;

- $\quad h_{t_{1}}^{G N S S}$ e $h_{t_{2}}^{G N S S}$ corresponde a altitude da estação GNSS para as épocas $t_{l}$ e $t_{2}$, respectivamente, referidas ao elipsoide;

- $\quad N_{1}$ e $N_{2}$ corresponde ao nível do mar obtido pelo marégrafo para as épocas $t_{1}$ e $t_{2}$, respectivamente, referidos ao zero da régua;

- $Z R_{t 1}$ e $Z R_{t 2}$ corresponde ao zero da régua (escala maregráfica) para as épocas $t_{1}$ e $t_{2}$, respectivamente;

- $\Delta N$ corresponde à diferença do nível do mar medida num marégrafo para as épocas $t_{1}$ e $t_{2}$, respectivamente (mudança relativa do nível do mar);

- $\Delta h$ corresponde diferença de altitude geodésica no mesmo ponto entre as épocas $t_{1}$ e época $t_{2}$;

- $\Delta H$ corresponde a variação absoluta do nível do mar (quanto subiu ou baixou, de fato, o nível na estação analisada). 


\subsection{Processamento e análises}

O processamento e análise dos dados das séries temporais foi realizada no modulo Análise de Maré @ versão 2016.09.01 do software AstGeoTop (GARNÉS, 2019), por ser uma ferramenta de desenvolvimento específica para tratar com dados maregráficos, tendo uma componente gráfica bastante iterativa com o usuário que permite visualização de comportamentos anômalos de dados na presença de outliers. Tem vários procedimentos de filtragem em cotas e datas, incluindo métodos iterativos com os harmônicos de maré. Possui modelos de predição e trabalha com regressão linear, polinomial quadrática e polinomial cúbica. Fornece as velocidades da variação do nível do mar com as respectivas incertezas: 1 sigma (68\% nível de confiança) e 1,966 sigma (95\% de nível de confiança). Na versão utilizada, permite trabalhar com 1.048.558 cotas de maré. Uma descrição mais detalhada das ferramentas disponíveis pode ser encontrada em (CALADO; GARNÉS; JAMUR, 2018).

Neste trabalho, no entanto, não foram realizadas filtragens a menos de quando se usava números 999 nos dados originais, para representar a ausência de uma observação.

Os modelos de regressão disponíveis para a análise foram o linear, o polinomial quadrático e o polinomial cúbico, Equações 2, 3 e 4 respectivamente:

$$
\begin{gathered}
y=a t+b \\
y=a t^{2}+b t+c \\
y=a t^{3}+b t^{2}+c t+d
\end{gathered}
$$

sendo: y o valor da cota ou da altitude observada em metros; a, b, c, d são os parâmetros do modelo de ajuste; t é a época da observação (usou-se dias julianos em relação a uma época média).

Qualquer um dos modelos das Equações 2, 3 ou 4, pode ser colocado na forma matricial como apresentado na Equação 5:

$$
y=A x+\varepsilon
$$

sendo: $\boldsymbol{y}$ um vetor m-dimensional contendo as observações; $A$ é a matriz de coeficientes dos parâmetros; $\boldsymbol{x}$ o vetor n-dimensional dos parâmetros; e $\varepsilon$ o vetor m-dimensional de erros aleatórios.

A estimativa pelo Método dos Mínimos Quadrados desse sistema, pode ser obtida por meio das equações normais (GEMAEL; MACHADO; WANDRESEN, 2015):

$$
x=\left(A^{T} A\right)^{-1} A^{T} y
$$

Os resíduos estimados $(v=-\varepsilon)$, a variância da unidade peso estimada $\left(\hat{\sigma}_{0}^{2}\right)$ e a Matriz Variância Covariância dos parâmetros estimada $(\Sigma x)$, são obtidos, respectivamente, pelas equações 7,8 e 9:

$$
\begin{gathered}
V=A x-y \\
\hat{\sigma}_{0}^{2}=\frac{V^{T} V}{m-n} \\
\Sigma_{X}=\hat{\sigma}_{0}^{2}\left(A^{T} A\right)^{-1}
\end{gathered}
$$

A velocidade e a aceleração do movimento vertical (nível do mar ou placa litosférica) obtidas com os modelos de regressão é calculado pelas derivadas primeira (velocidade $=d y / d t)$ e segunda $\left(\right.$ aceleração $=d^{2} y / d t^{2}$ ) e as incertezas obtidas pela lei de propagação das covariâncias (GEMAEL; MACHADO; WANDRESEN, 2015):

$$
\sigma=\sqrt{G \Sigma_{X} G^{T}}
$$

sendo: $\boldsymbol{G}$ um vetor linha ( $1 x n)$ representando os coeficientes das equações de velocidade e de aceleração; e a 
matriz $\Sigma \mathrm{x}$, que aparece na Equação 10, uma submatriz da matriz $\Sigma_{x}$ que aparece na Equação 9.

As incertezas dadas pelos desvios padrão, devem ser convertidas adequadamente para representarem $\mathrm{mm} / \mathrm{ano}$ para a velocidade e $\mathrm{mm} / \mathrm{ano}^{2}$ para a aceleração.

\section{RESULTADOS E DISCUSSÕES}

Douglas (1991; 1995), demonstrou que apenas registros de maré que abrangem mais de 50 anos são capazes de fornecer estimativas estáveis das taxas relativas do nível do mar, devido à forte variabilidade interdecadal que os registros de marés contêm. Entretanto, neste estudo, inclui-se marégrafos com menos de 50 anos para poder ter uma melhor representação da área em estudo.

\subsection{Nível relativo do mar}

A tendência do nível relativo do mar foi obtida utilizando a regressão linear, onde os valores calculados estão apresentados na Tabela 3 e são discutidos em seguida. Destaca-se que as incertezas apresentam 95\% de confiança e a cota média, máxima e mínima são parâmetros importantes para entender o comportamento local da maré.

Tabela 3 - Resultado da regressão linear para as estações maregráficas: $\left({ }^{* * *}\right)$ Estações com séries $\geq$ que 50 anos; $\left({ }^{++}\right)$ Estações com series $\geq$ que 30 anos; $\left(^{\#}\right)$ Estações com séries $\geq$ que 20 anos.

\begin{tabular}{|c|c|c|c|c|c|c|}
\hline \multirow[b]{2}{*}{ Id da Estação } & \multirow[b]{2}{*}{ Nome da Estação e País } & \multirow[b]{2}{*}{$\begin{array}{c}\mathrm{N}^{\circ} \text { de } \\
\text { anos }\end{array}$} & \multicolumn{4}{|c|}{ Relatório Estatístico } \\
\hline & & & Cota Média (m) & $\begin{array}{c}\text { Cota } \\
\text { Máxima } \\
(\mathbf{m})\end{array}$ & $\begin{array}{l}\text { Cota } \\
\text { Mínima } \\
(\mathrm{m})\end{array}$ & $\begin{array}{c}\text { Regressão Linear } \\
\text { (mm/ano) }\end{array}$ \\
\hline 157 & ***Buenos Aires, AR & 83 & 6,998 & 7,482 & 6,652 & $1,55 \pm 0,27$ \\
\hline 223 & $* * *$ Quequen, $\mathrm{AR}$ & 65 & 6,961 & 7,280 & 6,680 & $0,82 \pm 0,33$ \\
\hline 819 & ***Mar Del Plata, AR & 60 & 7,046 & 7,380 & 6,810 & $1,22 \pm 0,36$ \\
\hline 832 & $* * *$ Palermo, AR & 60 & 7,017 & 7,484 & 6,678 & $1,80 \pm 0,48$ \\
\hline 542 & "Imbituba, BR & 20 & 7,068 & 7,295 & 6,838 & $0,99 \pm 1,52$ \\
\hline 556 & ${ }^{\#}$ Recife, BR & 20 & 6,969 & 7,104 & 6,844 & $-0,26 \pm 1,04$ \\
\hline 578 & "Salvador, BR & 20 & 6,924 & 7,055 & 6,817 & $2,30 \pm 1,03$ \\
\hline 580 & \#Belém, BR & 20 & 7,068 & 7,332 & 6,905 & $0,00 \pm 1,73$ \\
\hline 726 & $* * *$ Cananéia, BR & 53 & 6,932 & 7,192 & 6,663 & $4,13 \pm 0,42$ \\
\hline 1032 & $* * *$ Ilha fiscal, BR & 54 & 6,928 & 7,212 & 6,544 & $2,22 \pm 0,50$ \\
\hline 510 & $* * *$ Antofagasta $2, \mathrm{CL}$ & 72 & 7,025 & 7,352 & 6,832 & $-0,90 \pm 0,19$ \\
\hline 571 & $* * *$ Talcahuano, CL & 68 & 6,966 & 7,265 & 6,785 & $0,67 \pm 0,27$ \\
\hline 619 & ${ }^{++}$Caldera, CL & 41 & 7,000 & 7,325 & 6,831 & $2,94 \pm 0,39$ \\
\hline 2261 & ${ }^{++}$Iquique II, CL & 33 & 6,973 & 7,224 & 6,831 & $-0,71 \pm 0,65$ \\
\hline 456 & Buenaventura, CO & 29 & 7,065 & 7,228 & 6,831 & $1,16 \pm 1,00$ \\
\hline 572 & ${ }^{++}$Cartagena, $\mathrm{CO}$ & 44 & 7,091 & 7,326 & 6,878 & $5,38 \pm 0,40$ \\
\hline 544 & ${ }^{++}$La Libertad II, EC & 46 & 7,000 & 7,319 & 6,729 & $-1,02 \pm 0,45$ \\
\hline 458 & ${ }^{\#}$ Matarani, PE & 29 & 7,073 & 7,205 & 6,943 & $-1,08 \pm 0,61$ \\
\hline 475 & ${ }^{\#}$ Talara, $\mathrm{PE}$ & 28 & 7,043 & 7,242 & 6,919 & $0,92 \pm 0,75$ \\
\hline 1274 & ${ }^{++}$Callao 2, PE & 47 & 7,008 & 7,350 & 6,846 & $-0,36 \pm 0,45$ \\
\hline
\end{tabular}

Fonte: Os autores (2020).

Como pode ser visto na Tabela 3, quanto maior o número de anos da série temporal maior é a precisão obtida na regressão linear. Isso se dá por conta da propagação das covariâncias no cálculo da precisão dos parâmetros estimados.

Nas estações com mais de 50 anos, destacadas com (***), a regressão linear indicou o maior aumento do nível do mar na estação de Cananéia-BR, com 4,13 \pm 0,42 mm/ano, e o maior rebaixamento na estação de Antofagasta 2, no Chile, com $-0,90 \pm 0,19 \mathrm{~mm} /$ ano. Vale ressaltar que as quatros estações da Argentina possuem mais de 50 anos e possuem coerência nos seus resultados, com o nível do mar variando de 0,82 $\mathrm{mm} / \mathrm{ano}$ até $1,80 \mathrm{~mm} / \mathrm{ano}$.

Nas estações com mais de 30 anos, destacadas com (++), a estação de Cartagena, na Colômbia, teve 
um aumento de 5,38 \pm 0,40 mm/ano no nível do mar e a estação de La Libertad II, no Equador, apresentou o maior rebaixamento, com uma taxa de $-1,02 \pm 0,45 \mathrm{~mm} / \mathrm{ano}$.

Já nas estações com mais de 20 anos, destacadas com (\#), a estação de Salvador, no Brasil, apresentou uma taxa de elevação de $2,30 \pm 1,03 \mathrm{~mm} / \mathrm{ano}$, sendo essa a de maior taxa positiva, e o maior rebaixamento foi observado na estação Matarani, no Peru, com uma taxa de $-1,08 \pm 0,61 \mathrm{~mm} / \mathrm{ano}$.

Comparando os resultados com outros autores, no marégrafo de Cananeia, ${ }^{1}$ Albarici, Guimarães e Trabanco (2018), encontraram um aumento de 3,8 mm/ano para o período de 1955-2007, sendo coerente com os valores encontrados para esta estação neste estudo e o mesmo período para ambos os estudos.

Em Imbituba, ${ }^{2}$ Dalazoana e De Freitas (2006) evidenciaram uma elevação no nível do mar de 2,0 $\mathrm{mm} /$ ano, integrando altimetria por satélite, dados da série temporal disponível pelo PSMSL e dados digitais de 2001 a 2004. Ainda em IMBITUBA, Da ${ }^{3}$ Silva, De Freitas e Dalazoana (2016) obtiveram uma elevação em torno de 2,4 mm/ano a partir de séries temporais de processamento GNSS, associadas com séries maregráficas de 2007 a 2014. Finalizando IMBITUBA, ${ }^{4} \mathrm{Da}$ Silva (2017) obteve como tendência do marégrafo uma elevação de 3,1 mm/ano no nível do mar, utilizando a integração de séries temporais de três centros (1948 a 1968; 2001 a 2016) e utilizando a série de 1948 a 1968 obteve uma elevação de cerca de 1,2 mm/ano.

Para os marégrafos da Argentina, ${ }^{5}$ Fiore et al. (2008), observaram nas estações de BUENOS AIRES (1905-2006), MAR DEL PLATA (1953-2006) e QUEQUEN (1918-1981), um aumento do nível do mar de $1,67 \mathrm{~mm} / \mathrm{ano}, 1,53 \mathrm{~mm} /$ ano e $1,6 \mathrm{~mm} / \mathrm{ano}$, respectivamente.

${ }^{6}$ López, Cevallos e Torres (2017), verificaram as tendências do nível do mar no Oceano Pacífico em 23 estações: duas na Colômbia, cinco no Equador, uma no Peru e 15 no Chile, e os seus resultados estão coerentes com os apresentados neste trabalho, com exceção do marégrafo de La Libertad.

As comparações descritas anteriormente estão apresentadas no Quadro 1.

Quadro 1 - Comparação entre tendência (velocidade) do nível relativo do mar obtida pelos autores com outros autores: ${ }^{1}$ Albarici, Guimarães e Trabanco (2018); ${ }^{2}$ Dalazoana e De Freitas (2006); ${ }^{3}$ Da Silva, De Freitas e Dalazoana (2016); ${ }^{4}$ Da Silva (2017); ${ }^{5}$ Fiore et al. (2008); ${ }^{6}$ López, Cevallos e Torres (2017).

\begin{tabular}{|c|c|c|}
\hline Marégrafo & Tendência (os autores) & Outros autores \\
\hline Cananéia & $(4,13 \pm 0,42) \mathrm{mm} / \mathrm{ano}(1954-2006)$ & $3,8 \mathrm{~mm} / \mathrm{ano}(1955-2007)^{1}$ \\
\hline Imbituba & \multirow{4}{*}{$(0,99 \pm 1,52) \mathrm{mm} / \mathrm{ano}(1948-1968)$} & $2,0 \mathrm{~mm} / \mathrm{ano}(1948-1968 \text { e } 2001-2004)^{2}$ \\
\hline Imbituba & & $2,4 \mathrm{~mm} /$ ano $(2007 \text { a } 2014)^{3}$ \\
\hline Imbituba & & $3,1 \mathrm{~mm} /$ ano $(1948-1968 \text { e } 2001-2016)^{4}$ \\
\hline Imbituba & & $1,2 \mathrm{~mm} / \mathrm{ano}(1948-1968)^{4}$ \\
\hline Buenos Aires & $(1,55 \pm 0,27) \mathrm{mm} / \mathrm{ano}(1905-1987)$ & $1,67 \mathrm{~mm} / \mathrm{ano}(1905-2006)^{5}$ \\
\hline Mar Del Plata & $(1,22 \pm 0,36) \mathrm{mm} / \mathrm{ano}(1957-2017)$ & $1,53 \mathrm{~mm} / \mathrm{ano}(1953-2006)^{5}$ \\
\hline Quequen & $(0,82 \pm 0,33) \mathrm{mm} / \mathrm{ano}(1918-1982)$ & $1,60 \mathrm{~mm} / \mathrm{ano}(1918-1981)^{5}$ \\
\hline Buenaventura & $(1,16 \pm 1,00) \mathrm{mm} / \mathrm{ano}(1941-1969)$ & $2,3 \mathrm{~mm} / \mathrm{ano}(1953-2014)^{6}$ \\
\hline Callao & $(-0,36 \pm 0,45) \mathrm{mm} /$ ano $(1970-2016)$ & $-0,3 \mathrm{~mm} /$ ano $(1970-2016)^{6}$ \\
\hline La Libertad & $(-1,02 \pm 0,45) \mathrm{mm} /$ ano $(1948-1994)$ & 5,70 mm/ano $(1949-2016)^{6}$ \\
\hline Antofagasta & $(-0,90 \pm 0,19) \mathrm{mm} / \mathrm{ano}(1945-2017)$ & $-0,80 \mathrm{~mm} /$ ano $(1945-2016)^{6}$ \\
\hline Caldera & $(2,94 \pm 0,39) \mathrm{mm} / \mathrm{ano}(1950-1991)$ & $1,20 \mathrm{~mm} / \mathrm{ano}(1950-2015)^{6}$ \\
\hline Talcahuano & $(0,67 \pm 0,27) \mathrm{mm} / \mathrm{ano}(1949-2017)$ & $1,00 \mathrm{~mm} / \mathrm{ano}(1949-2015)^{6}$ \\
\hline
\end{tabular}

Fonte: Os autores (2020).

Na Figura 3, as séries mensais dos marégrafos são apresentadas, junto com sua tendência e a sua aceleração. As estações foram agrupadas por países para verificar uma possível correlação nos dados e para representar as séries temporais em um mesmo gráfico foi necessário acrescentar ou diminuir um valor constante na série temporal de alguns marégrafos, conforme está descrito na legenda da imagem (exemplo, Quequen $(+0,8 \mathrm{~m}))$. 
Figura 3 - Médias mensais do nível do mar a partir dos dados do PSMSL (a) Marégrafos da Argentina; (b) Marégrafos do Norte e Nordeste do Brasil; (c) Marégrafos do Sudeste e Sul do Brasil; (d) Marégrafos do Chile; (e) Marégrafos da Colômbia; (f) Marégrafo do Equador; (g) Marégrafos do Peru.
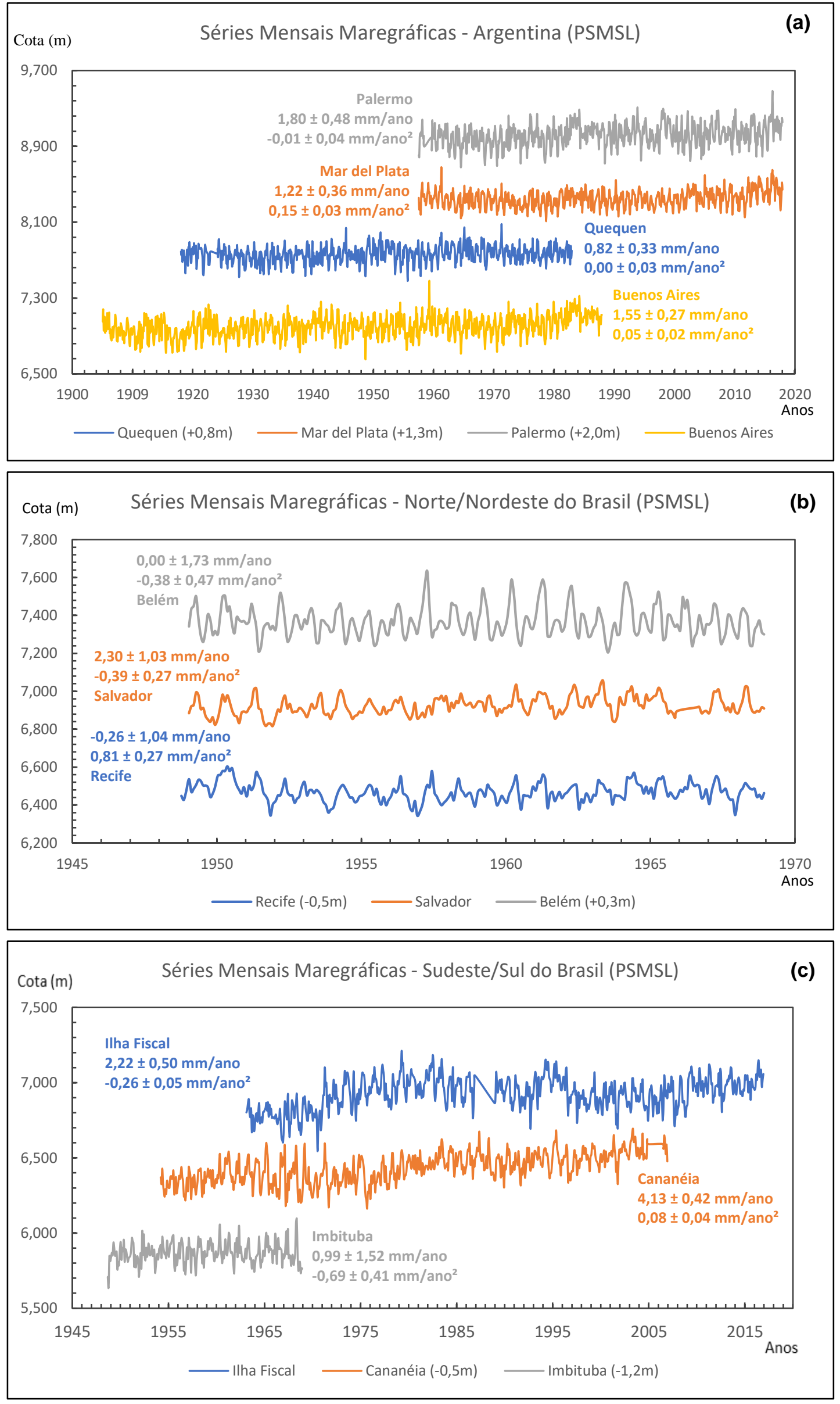

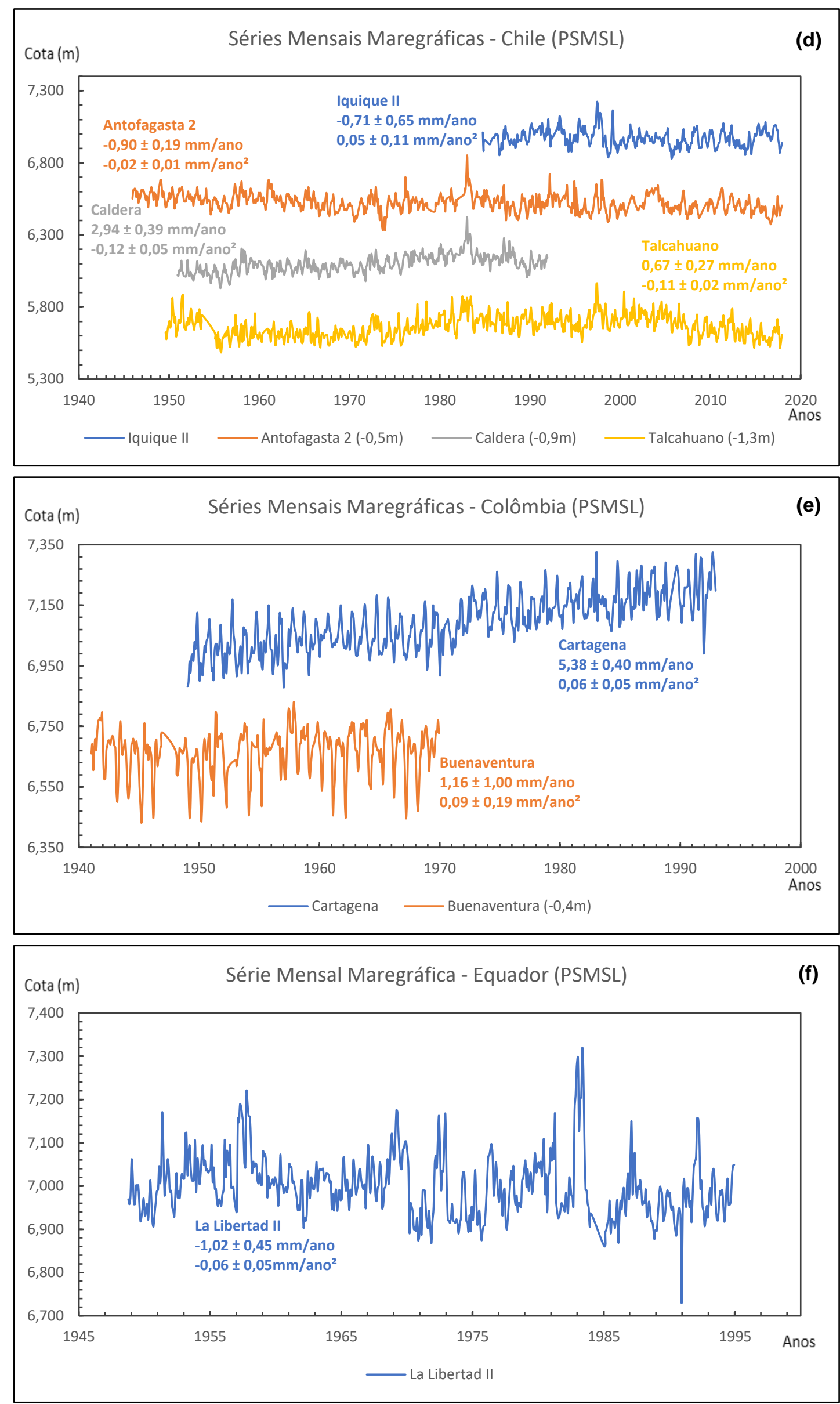


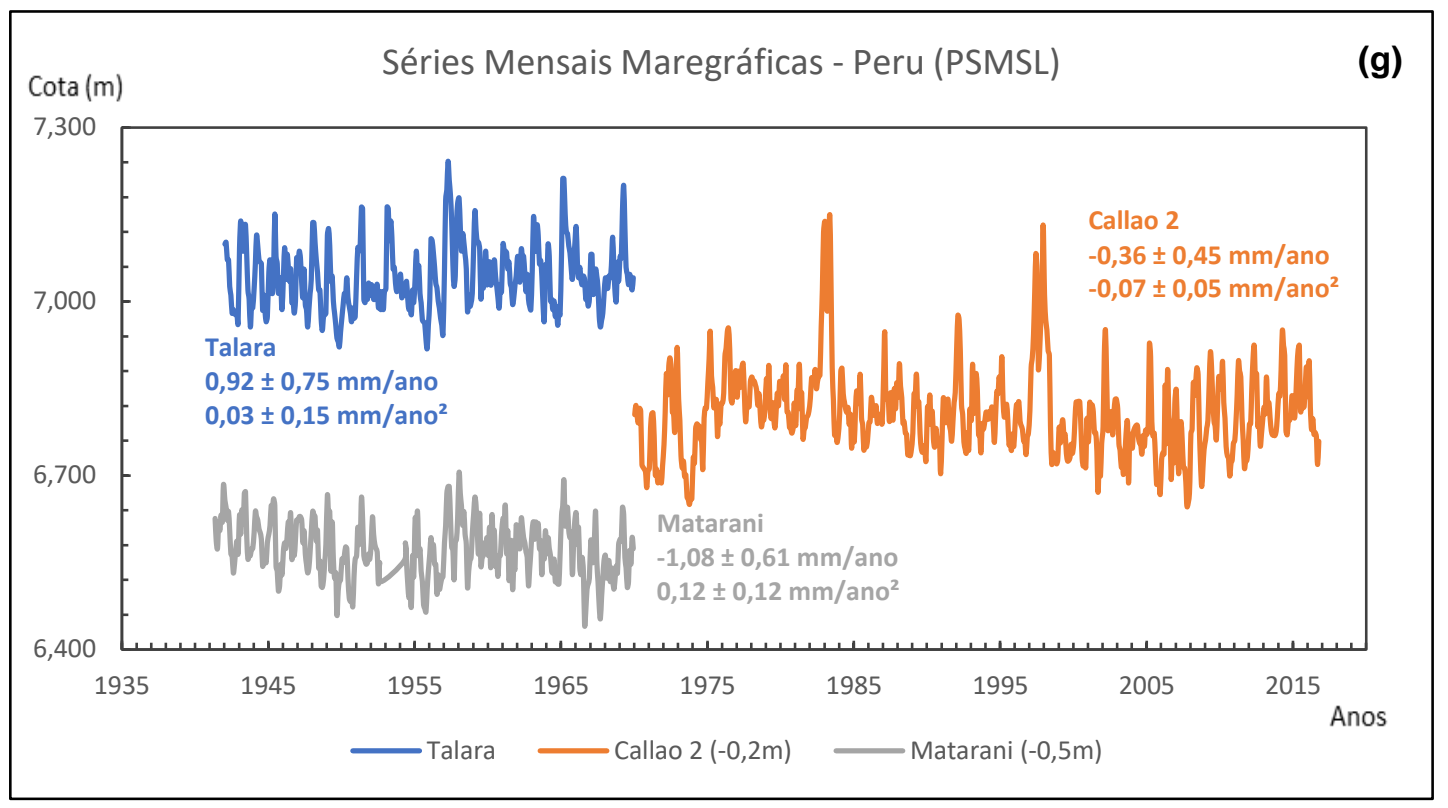

Fonte: Os autores (2020).

Na Figura 3a, é possível ver picos positivos entre os anos 1957 e 1959, entre os anos de 1972 e 1973, e no ano de 2015 e 2016. Na Figura 3d observa-se também os picos nos anos 1982/1983 e 1997/1998. Esses picos se apresentam também nas Figuras 3e, 3f e 3g. É possível observar os picos de 1982/83 e 1997/98 nitidamente na estação Callao 2, Figura 3g. Esses picos, geralmente, são devidos a tsunamis ou eventos climáticos, como por exemplo El Nino. Ferreira et al (2017), classificam o El Nino de 1972/73 como forte, e os de 1982-83, 1997-98 e 2015-2016, como muito forte, explicando, possivelmente, esses picos registrados pelos marégrafos.

Ainda na Figura 3, tem-se o resultado da regressão polinomial quadrática. Esta regressão auxilia na compreensão dos resultados da análise por regressão linear. Quando a regressão linear indica um aumento do nível do mar (tendência positiva '+') e a concavidade da parábola obtida na regressão quadrática for voltada para cima (aceleração positiva '+'), indica que essa elevação continuará aumentando por algum tempo. Caso contrário, com a parábola voltada para baixo (aceleração negativa '-'), indica que esse aumento passará a diminuir em algum momento. Quando a regressão linear indica um rebaixamento do nível do mar (tendência negativa '-') e a concavidade da parábola obtida na regressão quadrática for voltada para cima (aceleração positiva '+'), indica que esse rebaixamento irá diminuir com o tempo. Caso contrário, com a parábola voltada para baixo (aceleração negativa '-'), indica que esse rebaixamento ainda continuará acontecendo por um tempo.

Como exemplo, pode-se observar o marégrafo de Cananeia (Figura 3c), no Brasil, com um aumento de 4,13 mm/ano indicado na regressão linear e a concavidade da parábola voltada para cima (aceleração +0,08 \pm 0,04 mm/ano ${ }^{2}$, no período de 1954-2006, indicando que a elevação continuará por um tempo. Albarici, Guimarães e Trabanco (2018) encontraram uma taxa de aumento do nível do mar para Cananeia de $7 \mathrm{~mm} / a n o$ para o período de 2012-2015, indicando assim, esse aumento.

Para o marégrafo de Caldera (Figura 3d), no Chile, no período de 1950-1991, é observado uma taxa de elevação do nível do mar de 2,94 mm/ano e a concavidade da parábola é voltada para baixo (aceleração $\left.0,12 \pm 0,05 \mathrm{~mm} / \mathrm{ano}^{2}\right)$, indicando que esse aumento diminuirá com o decorrer do tempo. López (2012), encontra para o marégrafo de Caldera, no período de 1950-2006, uma taxa de elevação 1,2 mm/ano, indicando essa redução no aumento do nível do mar com o decorrer do tempo.

\subsection{Movimentação vertical crustal}

Para obter a movimentação vertical crustal, avaliou-se as altitudes geodésicas $(h)$ disponibilizadas pelas coordenadas semanais do SIRGAS-CON, das estações GNSS da rede. Vale salientar que a utilização desses dados para corrigir movimentos verticais de origem não tectônica não é aconselhável (IBGE, 2016).

A Tabela 4 apresenta a distância aproximada entre a estação GNSS e o marégrafo, o movimento 
vertical observado na estação GNSS por meio da regressão linear, o período dos dados avaliado, o movimento vertical obtido no SIR15P01 (SANCHEZ e DREWES, 2016) e seu período, e o movimento vertical obtido no SIR17P1 (SANCHEZ, 2017) e seu período.

Tabela 4 - Resultados da movimentação vertical crustal das estações GNSS por regressão linear: ${ }^{1}$ Sánchez e Drewes

\begin{tabular}{|c|c|c|c|c|c|c|c|}
\hline Id & $\begin{array}{c}\text { GNSS } \\
\text { Marégrafo } \\
\text { dist. (m) }\end{array}$ & $\begin{array}{c}\text { Movimento } \\
\text { Vertical } \\
\text { (mm/ano) }\end{array}$ & $\begin{array}{c}\text { Período } \\
\text { Início } \\
\text { Fim } \\
\end{array}$ & $\begin{array}{c}{ }^{1} \text { Movimento } \\
\text { Vertical } \\
\text { (mm/ano) }\end{array}$ & $\begin{array}{c}\text { Período } \\
\text { Início } \\
\text { Fim } \\
\end{array}$ & $\begin{array}{c}{ }^{2} \text { Movimento } \\
\text { Vertical } \\
\text { (mm/ano) }\end{array}$ & $\begin{array}{c}\text { Período } \\
\text { Início } \\
\text { Fim } \\
\end{array}$ \\
\hline IGM1 & $\sim 7338$ & $-0,69 \pm 0,12$ & $\begin{array}{l}11 / 2003 \\
12 / 2018 \\
\end{array}$ & $-3,2 \pm 0,7$ & $\begin{array}{l}04 / 2011 \\
04 / 2015 \\
\end{array}$ & $-1,3 \pm 0,9$ & $\begin{array}{l}04 / 2011 \\
01 / 2017 \\
\end{array}$ \\
\hline MPL2 & $\sim 6$ & $-0,70 \pm 0,27$ & $\begin{array}{l}11 / 2009 \\
12 / 2018 \\
\end{array}$ & $-2,1 \pm 0,6$ & $\begin{array}{l}04 / 2010 \\
04 / 2015 \\
\end{array}$ & $-2,1 \pm 1,1$ & $\begin{array}{l}10 / 2014 \\
01 / 2017 \\
\end{array}$ \\
\hline BELE & $\sim 6260$ & $-1,65 \pm 0,17$ & $\begin{array}{l}01 / 2004 \\
12 / 2018\end{array}$ & $-2,6 \pm 0,1$ & $\begin{array}{l}04 / 2010 \\
04 / 2015\end{array}$ & $-0,3 \pm 0,6$ & $\begin{array}{l}04 / 2011 \\
01 / 2017\end{array}$ \\
\hline IMBT & $\sim 670$ & $-1,38 \pm 0,17$ & $\begin{array}{l}09 / 2007 \\
12 / 2018 \\
\end{array}$ & $-3,4 \pm 0,3$ & $\begin{array}{l}03 / 2010 \\
04 / 2015 \\
\end{array}$ & $-2,0 \pm 0,7$ & $\begin{array}{l}04 / 2011 \\
01 / 2017\end{array}$ \\
\hline NEIA & $\sim 10$ & $-2,66 \pm 0,40$ & $\begin{array}{l}01 / 2006 \\
12 / 2018 \\
\end{array}$ & $-4,6 \pm 0,4$ & $\begin{array}{l}09 / 2012 \\
04 / 2015 \\
\end{array}$ & $-3,9 \pm 0,7$ & $\begin{array}{l}09 / 2012 \\
10 / 2016 \\
\end{array}$ \\
\hline ONRJ & $\sim 5993$ & $1,04 \pm 0,30$ & $\begin{array}{l}04 / 2007 \\
12 / 2018 \\
\end{array}$ & $0,1 \pm 0,2$ & $\begin{array}{l}04 / 2010 \\
06 / 2013 \\
\end{array}$ & $0,8 \pm 0,6$ & $\begin{array}{l}03 / 2015 \\
01 / 2017 \\
\end{array}$ \\
\hline RECF & $\sim 9353$ & $-2,05 \pm 0,07$ & $\begin{array}{l}01 / 2000 \\
02 / 2018\end{array}$ & $-3,3 \pm 0,4$ & $\begin{array}{l}09 / 2012 \\
03 / 2015\end{array}$ & $-2,2 \pm 0,7$ & $\begin{array}{l}04 / 2011 \\
11 / 2017\end{array}$ \\
\hline SSA1 & $\sim 157$ & $-0,48 \pm 0,13$ & $\begin{array}{l}09 / 2007 \\
12 / 2018\end{array}$ & $-3,5 \pm 0,2$ & $\begin{array}{l}04 / 2011 \\
04 / 2015\end{array}$ & $-2,3 \pm 0,6$ & $\begin{array}{l}10 / 2012 \\
05 / 2015\end{array}$ \\
\hline IQQE & $\sim 7308$ & $1,23 \pm 0,29$ & $\begin{array}{l}02 / 2002 \\
12 / 2018\end{array}$ & $2,5 \pm 1,1$ & $\begin{array}{l}04 / 2010 \\
03 / 2014\end{array}$ & $-2,1 \pm 1,4$ & $\begin{array}{l}04 / 2015 \\
01 / 2017\end{array}$ \\
\hline BUEN & $\sim 7868$ & $-0,08 \pm 0,12$ & $\begin{array}{l}10 / 2005 \\
12 / 2018 \\
\end{array}$ & $0,3 \pm 0,7$ & $\begin{array}{l}04 / 2010 \\
03 / 2015\end{array}$ & $0,5 \pm 1,1$ & $\begin{array}{l}10 / 2012 \\
01 / 2017\end{array}$ \\
\hline CART & $\sim 1442$ & $-1,86 \pm 0,07$ & $\begin{array}{l}02 / 2000 \\
12 / 2018 \\
\end{array}$ & $-0,2 \pm 1,4$ & $\begin{array}{l}01 / 2013 \\
12 / 2014\end{array}$ & $-0,2 \pm 1,1$ & $\begin{array}{l}01 / 2013 \\
11 / 2016\end{array}$ \\
\hline CALL & $\sim 1435$ & $3,37 \pm 0,23$ & $\begin{array}{l}07 / 2009 \\
04 / 2018\end{array}$ & $3,6 \pm 0,7$ & $\begin{array}{l}03 / 2010 \\
04 / 2015\end{array}$ & $3,6 \pm 0,8$ & $\begin{array}{l}04 / 2011 \\
01 / 2017\end{array}$ \\
\hline
\end{tabular}

Fonte: Os autores (2020)

A fim de comparação dos resultados obtidos, o relatório da Rede Maregráfica Permanente para Geodésia (RMPG) do IBGE (IBGE, 2016), indica um rebaixamento na placa de 0,48 mm/ano na estação SSA1, e o resultado obtido com os dados da rede SIRGAS-CON indicou um rebaixamento de 0,5 mm/ano.

Para a estação IMBT, o mesmo relatório indica uma taxa de rebaixamento da placa de 2,6 mm/ano, e com os dados aqui analisados é possível observar um rebaixamento de 1,38 mm/ano. Também para comparação, as soluções Multianuais da rede SIRGAS-CON estão apresentadas na Tabela 4 e apontam coerência com os resultados aqui obtidos, com exceção da estação IQQE que apresenta uma pequena divergência e deve ser investigada em trabalhos futuros.

Comparando com outros autores, Da Silva (2017) encontrou um rebaixamento de 3,02 mm/ano da componente altimétrica para o período de 2007 a 2016 na estação de Imbituba e Da Silva e De Freitas (2015) encontraram o valor de rebaixamento na estação IMBT de $0,2 \mathrm{~mm} / \mathrm{ano}$.

Para estação CART, Bosch (2005) encontrou uma taxa de rebaixamento de 5,5 mm/ano e neste trabalho é possível observar na estação CART um rebaixamento de $1,86 \mathrm{~mm} / \mathrm{ano}$. Vale ressaltar que a estação CART é a que possuí a maior defasagem na série dos dados, com $57,47 \%$ de dados faltantes (indicado na Tabela 2), atrapalhando assim, uma análise mais realista.

A estação de NEIA, que está localizada a 10 metros do marégrafo, possui uma taxa de rebaixamento de -2,66 mm/ano. Essa observação da estação NEIA é importante, pois a estação maregráfica de Cananéia apresentou uma variação do nível relativo do mar significativamente superior às demais estações brasileiras, podendo ser justificada com os dados da rede SIRGAS-CON que apontam uma variação crustal significativa. Esse rebaixamento contribui, parcialmente, para o valor exagerado da elevação do nível do mar na estação de Cananeia.

A menos da estação ONRJ que deve possuir uma peculiaridade a ser investigada, todas as demais estações na costa leste do continente Sul-Americano tiveram rebaixamento, com a taxa média de 1,37 mm/ano. 
Do outro lado, no Pacífico, por conta da subducção da placa de Nazca sob a placa SOAM há uma elevação média de 2,3 mm/ano, conforme mostram os resultados das estações CALL e IQQE. Um pouco mais ao norte devido a influência da placa de Cocos e da placa do Caribe na placa SOAM, as estações BUEN e CART têm um rebaixamento de $0,68 \mathrm{~mm} / \mathrm{ano}$ e $1,86 \mathrm{~mm} / \mathrm{ano}$.

\subsection{Nível absoluto do mar}

O último resultado deste trabalho, foi a obtenção da taxa do nível absoluto do mar, obtido da soma das taxas do nível relativo do mar, dado pelo marégrafo, com a taxa de movimento vertical crustal, dada pelo GNSS. A Tabela 5 apresenta os resultados.

Tabela 5 - Nível absoluto do mar nas estações maregráficas.

\begin{tabular}{c|c|c|c|c|c}
\hline Período & $\begin{array}{c}\Delta \mathbf{N} \\
(\mathbf{m m} / \mathbf{a n o})\end{array}$ & $\begin{array}{c}\mathbf{\Delta} \\
(\mathbf{m m} / \mathbf{a n o})\end{array}$ & $\begin{array}{c}\mathbf{N M} \text { absoluto } \\
\mathbf{\Delta H} \\
(\mathbf{m m} / \mathbf{a n o})\end{array}$ & $\begin{array}{c}\text { Estação } \\
\text { Maregráfica }\end{array}$ & Estação GNSS \\
\hline $1905-2018$ & $1,55 \pm 0,27$ & $-0,69 \pm 0,12$ & $0,86 \pm 0,30$ & Buenos Aires, AR & IGM1 \\
\hline $1957-2018$ & $1,22 \pm 0,36$ & $-0,70 \pm 0,27$ & $0,52 \pm 0,45$ & Mar Del Plata, AR & MPL2 \\
\hline $1948-2018$ & $0,99 \pm 1,52$ & $-1,38 \pm 0,17$ & $-0,39 \pm 1,53$ & Imbituba, BR & IMBT \\
\hline $1948-2018$ & $-0,26 \pm 1,04$ & $-2,05 \pm 0,07$ & $-2,31 \pm 1,04$ & Recife, BR & RECF \\
\hline $1949-2018$ & $2,30 \pm 1,03$ & $-0,48 \pm 0,13$ & $1,82 \pm 1,04$ & Salvador, BR & SSA1 \\
\hline $1949-2018$ & $0,00 \pm 1,73$ & $-1,65 \pm 0,17$ & $-1,65 \pm 1,74$ & Belém, BR & NELE \\
\hline $1954-2018$ & $4,13 \pm 0,42$ & $-2,66 \pm 0,40$ & $1,47 \pm 0,58$ & Cananéia, BR & ONRJ \\
\hline $1963-2018$ & $2,22 \pm 0,50$ & $1,04 \pm 0,30$ & $3,26 \pm 0,58$ & Ilha Fiscal, BR & IQQE \\
\hline $1984-2018$ & $-0,71 \pm 0,65$ & $1,23 \pm 0,29$ & $0,52 \pm 0,71$ & Iquique II, CL & BUEN \\
\hline $1941-2018$ & $1,16 \pm 1,00$ & $-0,08 \pm 0,12$ & $1,08 \pm 1,01$ & Buenaventura, CO & Cartagena, CO \\
\hline $1949-2018$ & $5,38 \pm 0,40$ & $-1,86 \pm 0,07$ & $3,52 \pm 0,41$ & CART \\
\hline $1970-2018$ & $-0,36 \pm 0,45$ & $3,37 \pm 0,23$ & $3,01 \pm 0,51$ & Callao 2, PE & CALL \\
\hline
\end{tabular}

Fonte: Os autores (2020).

Na Figura 4 (AVISO, 2019), é possível observar a tendência do nível absoluto do mar obtido com dados de altimetria por satélite no período de setembro de 1992 a junho de 2018. Verifica-se que os resultados aqui apresentados estão coerentes com a estimativa para o nível do mar obtido com satélites altímetros.

As estações que apresentaram taxas negativas do nível absoluto do mar, (Imbituba, Recife e Belém), apresentaram um alto valor do sigma e como os valores do movimento crustal são coerentes com outros autores, possíveis problemas estão relacionados com os dados das séries maregráficas.

Figura 4 - Estimativa do Nível do Mar a partir das informações da AVISO.

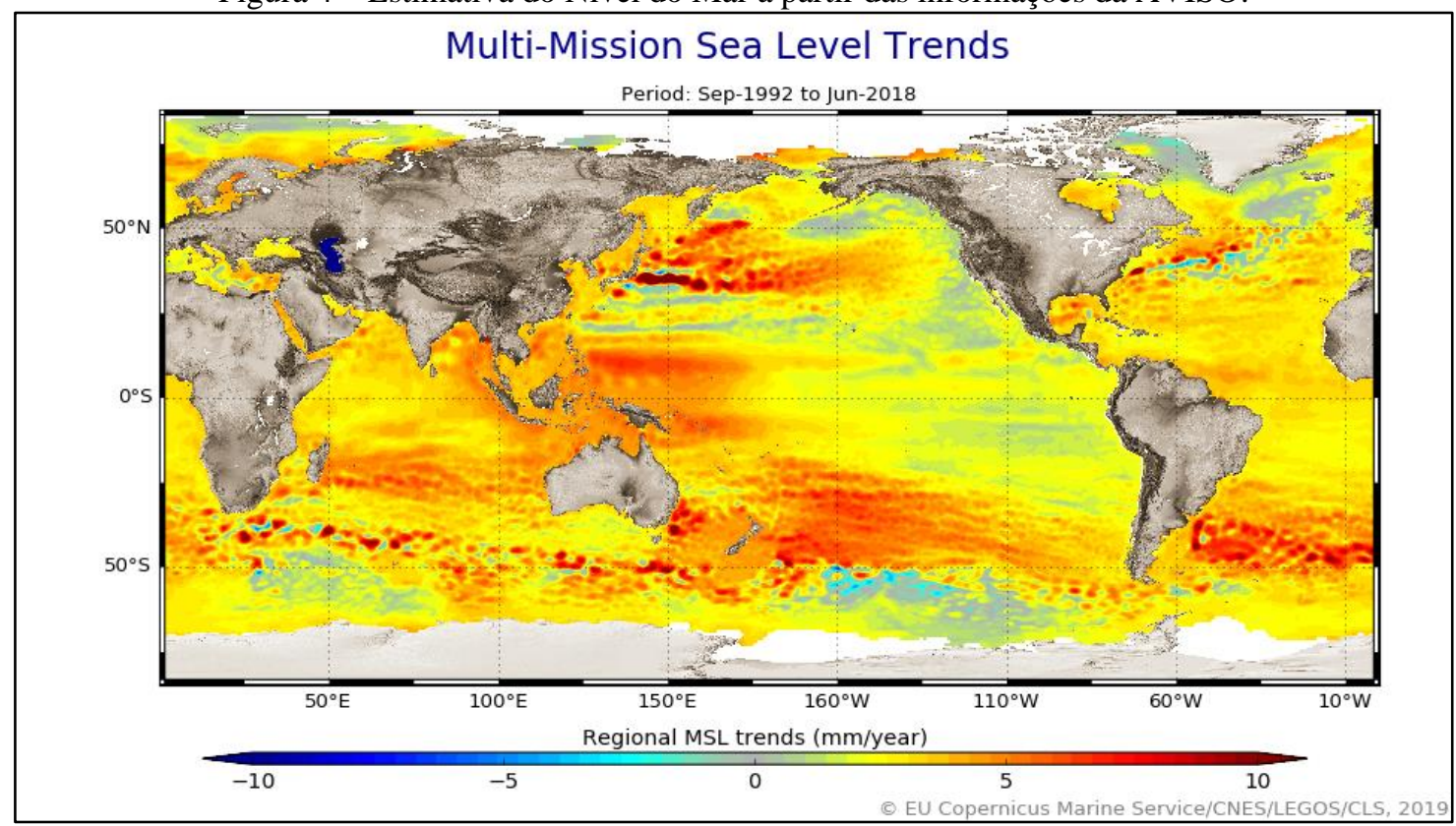

Fonte: Adaptada de AVISO (2019). 


\section{CONCLUSÕES E RECOMENDAÇÕES}

Neste trabalho foram executadas análises do nível relativo e absoluto do mar para a América de Sul. As estações maregráficas analisadas foram obtidas no banco de dados do PSMSL e separadas da seguinte forma: estações com mais de 50 anos de dados, em um total de oito estações; estações com mais de 30 anos de dados, em um total de cinco estações; estações com mais de 20 anos de dados, em um total de sete estações. Também foram utilizadas as coordenadas semanais de 12 estações da rede SIRGAS-CON, disponibilizadas pelo próprio SIRGAS, até a semana GPS 2033, no qual três estações possuem menos de 10 anos de dados, e dez estações possuem mais de 10 anos de dados.

As variações relativas do nível apresentaram taxas variando de $-0,71 \mathrm{~mm} / \mathrm{ano} \pm 0,65 \mathrm{~mm} /$ ano (Iquique II, no Chile) até 5,38 mm/ano $\pm 0,40 \mathrm{~mm} /$ ano (Cartagena, na Colômbia). Indicando rebaixamento e aumento do nível relativo do mar.

A movimentação vertical crustal, obtida com as coordenadas semanais do SIRGAS-CON, indica um rebaixamento médio da placa SOAM na costa brasileira de 1,64 mm/ano.

A variação absoluta do mar, apresentou um aumento de $0,98 \mathrm{~mm} / \mathrm{ano} \pm 0,93 \mathrm{~mm} / \mathrm{ano}$ na região de estudo, sendo compatível com os resultados do aumento do nível do mar global atual.

Como recomendação, sugere-se investigação integrando dados de satélites altímetros, principalmente nas estações discrepantes, como ONRJ, em relação ao movimento crustal, e RECF, para os dados maregráficos.

\section{Agradecimentos}

A Universidade Federal de Pernambuco (UFPE), por meio do Departamento de Engenharia Cartográfica (DECart) e do Programa de Pós-Graduação em Ciências Geodésicas e Tecnologias da Geoinformação (PGCGTG), que disponibilizaram suas instalações e aplicativos computacionais.

O presente trabalho foi realizado com apoio financeiro da CAPES (Coordenação de Aperfeiçoamento de Pessoal de Nível Superior), por meio do processo de número: 1695842.

\section{Contribuição dos Autores}

O autor Lucas Calado participou nas fases de coleta, processamento e análise dos dados, e também da metodologia e redação do texto. Silvio Garnés atuou na metodologia, no desenvolvimento do software, na análise dos dados e nas correções. Karoline Jamur contribuiu com a análise dos resultados, as adequações metodológicas e as correções textuais.

\section{Conflitos de Interesse}

Os autores declaram que não há conflitos de interesse.

\section{Referências}

ALBARICI, F. L.; GUIMARÃES, G. N.; TRABANCO, J. L. A. Análise relativa do nível médio do mar em Cananeia/SP. Revista Brasileira de Geomática, Curitiba, vol. 6, n.3, p. 176-193, jul/set 2018.

AVISO. Data: Mean Sea Level. Disponível em: <http://www.aviso.altimetry.fr/en/data/products/oceanindicators-products/mean-sea-level.html>. Acesso em: 4 fev. 2019.

BARBOSA, S. A. Sea level change in the North Atlantic from tide gauges and satellite altimetry. 284f. Tese (Doutorado em Engenharia Geográfica) - Faculdade de Ciências, Universidade do Porto, Porto, 2005.

BOSCH, W. Inter-Comission Project 1.1 - Satellite Altimetry - Mid-Term Report 2005. In: DREWES, H.; HORNIK, H. (Ed.). IAG Comission 1 - Reference Frames - Bulletin No 19 - Mid-Term Report 2005. Munich, 2005. p. 31-34. 
CALADO, L. G. L. P.; GARNÉS, S. J. A.; JAMUR, K. P. Análise da estação maregráfica de Fortaleza para determinar as variações do nível do mar. In: SIMPÓSIO BRASILEIRO DE CIÊNCIAS GEODÉSICAS E TECNOLOGIAS DA GEOINFORMAÇÃO, 7, 2018, Recife. Anais... Recife: Editora UFPE, 2018. p. 461-470.

DA SILVA, L. M. Análise da evolução temporal do Datum Vertical Brasileiro de Imbituba. 270 f. Tese (Doutorado em Ciências Geodésicas) - Setor de Ciências da Terra, Universidade Federal do Paraná, Curitiba, 2017.

DA SILVA, L. M.; DE FREITAS, S. R. C.; DALAZOANA, R. Análise de Séries Temporais Maregráficas correlacionadas com observações GNSS do Datum Vertical Brasileiro de Imbituba-SC. Revista Brasileira de Cartografia, Rio de Janeiro, v. 68, n. 1, p. 73-90, Jan/Fev 2016.

DA SILVA, L. M.; DE FREITAS, S. R. C. Estimativa da posição atual do Datum Vertical Brasileiro de Imbituba a partir de dados maregráficos, observações GNSS e Altimetria por Satélites. In: SIMPÓSIO SIRGAS, 2015, Santo Domingo, República Dominicana. Apresentação... 2015.

DALAZOANA, R.; DE FREITAS, S. R. C. Estudos Dirigidos à Análise Temporal do Datum Vertical Brasileiro. Boletim de Ciências Geodésicas: Resumos, Curitiba, v. 12, n. 1, p. 173-174, 2006.

DALAZOANA, R.; LUZ, R. T.; DE FREITAS, S. R. C. Estudos do NMM a partir de séries temporais maregráficas e de Altimetria por satélites visando a integração da rede vertical brasileira ao SIRGAS. Revista Brasileira de Cartografia, Rio de Janeiro, v. 57, n. 2, p. 140-153, Ago 2005.

DOUGLAS, B. C. Global Sea Level Rise. Journal of Geophysical Research, v. 96, n. C4, p. 6981-6992, April 1991.

DOUGLAS, B. C. Global Sea Rise: A redetermination. Surveys in Geophysics, v. 18, p. 279-292, May 1997.

FERREIRA, L. G. B., CARAMORI, P. H., MORAIS, H., NITSCHE, P. R., DA COSTA, A. B. F. O fenômeno El Niño de 2015/2016 e seus impactos nas chuvas do Paraná. LAPAR, Paraná, 2017.

FIORE, M.; ONOFRIO, E.; GRISMEYER, W.; MEDIAVILLA, D. El ascenso del nivel del mar em la costa de la provincia de Buenos Aires. Ciencia Hoy, v. 18, n. 106, p. 19-25, Ago/Set 2008.

GARNÉS, S. J A. AstGeoTop (2019). Módulo: Analise de maré @ versão 2016.09.01. Software. Departamento de Engenharia Cartográfica. Universidade Federal de Pernambuco, Recife, PE.

GEMAEL, C.; MACHADO, A. M. L.; WANDRESEN, R. Introdução ao ajustamento de observações: aplicações geodésicas. $2^{\text {a }}$ Edição. Curitiba: Editora UFPR, 2015.

GLOBAL GEODETIC OBSERVING SYSTEM (GGOS). The Global Geodetic Observing System: Introducing GGOS - Additional Information: GGOS Components. Disponível em: <http://www.ggos.org/>. Acesso em: 4 fev. 2019.

HOLGATE, S. J.; MATTHEWS, A.; WOODWORTH, P. L.; RICKARDS, L. J.; TAMISIEA, M. E.; BRADSHAW, E.; FODEN, P. R.; GORDON, K. M.; JEVREJEVA, S.; PUGH, J. New Data Systems and Products at the Permanent Service for Mean Sea Level. Journal of Coastal Research, v. 29, n. 3, p. 493$504,2013$.

INSTITUTO BRASILEIRO DE GEOGRAFIA E ESTATÍSTICA (IBGE). Análise do Nível Médio do Mar nas Estações da Rede Maregráfica Permanente para Geodésia - RMPG 2001/2015. Rio de Janeiro, 2016. Relatório Disponível em: <ftp://geoftp.ibge.gov.br/informacoes_sobre_posicionamento_geodesico/rmpg/relatorio/relatorio_RMPG _2001_2015_GRRV.pdf >. Acesso em: 4 fev. 2019.

IMBIE. Mass balance of the Antarctic Ice Sheet from 1992 to 2017. Nature International Journal of Science, v. 558, p. 219-222, 2018.

LÓPEZ, M. C. Variabilidad del nivel del mar en el Pacifico Sur Oriental: Costas de Chile. Revista Cientifica, Lima, Peru, v. 10, n. 1, p. 37-47, 2013.

LÓPEZ, M. C.; CEVAllos, J.; TORRES, R. Tendencias del nivel del mar em el litoral del Pacífico Sur Oriental. In: BOTELLO, A. V.; VILLANUEVA, S.; GUTIÉRREZ, J.; ROJAS-GALAVIZ, J. L. (eds) 
Vulnerabilidad de las zonas costeras de Lationamérica al cambio climático. UJAT, UNAM, UAC. 2017. p. 165-176.

PSMSL. Permanent Service For Mean Sea Level: "Tide Gauge Data". Disponível em: <http://www.psmsl.org/data/obtaining/>. Acesso em: 4 fev. 2019.

SÁNCHEZ L., DREWES H. SIR15P01: Multiyear solution for the SIRGAS Reference Frame. 2016. Disponível em: < https://doi.pangaea.de/10.1594/PANGAEA.862536>. Acesso em: 4 fev. 2019.

SÁNCHEZ L. SIRGAS reference frame realization SIR17P01. Technische Universitaet Muenchen, Deutsches Geodaetisches Forschungsinstitut DGFI-TUM, IGS RNAAC, 2017.

SIRGAS. Sistema de Referência Geocêntrico para as Américas. Disponível em: 〈http://www.sirgas.org> . Acesso em: 9 ago. 2019.

\section{Biografia do autor principal}

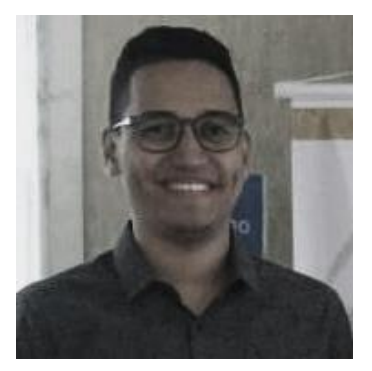

Lucas G. Lima P. Calado, natural de Barreiros-PE, 1993. Engenheiro Cartógrafo formado pela Universidade Federal de Pernambuco (UFPE) e Mestre em Ciências Geodésicas e Tecnologias da Geoinformação pela mesma instituição. Atualmente, atua como professor substituto no Departamento de Engenharia Cartográfica, no Campus Recife, da UFPE, ministrando a disciplina de Topografia para os cursos de Engenharia Cartográfica, Engenharia Civil, Engenharia de Minas e Geologia. Tem interesse de pesquisa nas áreas de Topografia, Geodésia Física e Geodésia Celeste. 